\title{
A importância da conscientização da IST na adolescência e como a enfermagem pode contribuir para a diminuição destas infecções
}

The importance of STIs awareness in adolescence and how nursing can contribute to the reduction of these infections

La importancia de la conciencia de ITS en la adolescencia y cómo enfermería puede contribuir a la reducción de estas infecciones

Recebido: 04/10/2021 | Revisado: 10/10/2021 | Aceito: 13/10/2021 | Publicado: 16/10/2021

Lidiane Cristina Montanholi de Mendonça Azevedo

ORCID: https://orcid.org/0000-0002-5783-4319 Faculdade Cristo Rei, Brasil

E-mail: lidianeazevedo210@gmail.com

Marli de Oliveira Costa

ORCID: https://orcid.org/0000-0002-9616-4477

Faculdade Cristo Rei, Brasil

E-mail: marli@faccrei.edu.br

\begin{abstract}
Resumo
Este estudo é de abordagem qualitativa e caráter explicativo-bibliográfico. Fundamenta-se em Bonfim (2012), Nunes e Silva (2001), Valle e Mattos (2010), Benetti (1990), Costa e Silva (2019) Ministério da Saúde (2021) e entre outros autores que abordam o tema. Como objetivo central buscou-se definir quais as principais causas e tratamentos da IST no Brasil. Busca-se elucidar a seguinte questão: de que maneira a enfermagem pode contribuir de forma significativa para a conscientização das infecções causadas pela IST na adolescência? Inicialmente apresentam-se os conceitos de Aids no Brasil, DST para IST e Sexualidade. É necessário criar a vivência de uma sexualidade ética, qualitativa e pautada na responsabilidade afetiva e corporal especialmente na fase da adolescência. Sendo assim os objetivos específicos que possibilitaram os resultados e a compreensão desta temática são: Realizar um breve histórico sobre as raízes da adolescência e sobre o início da AIDS no Brasil. Descrever quais são as IST frequentes transmissíveis de maior contágio para os adolescentes. Verificar como o profissional de saúde é essencial para que haja uma conscientização adequada entre os jovens na sua sexualidade. Considerar as formas de tratamentos possíveis para a IST e sua aplicação no cotidiano atual. Considerar o papel da família na busca do entendimento sexual dos jovens. O processo de pesquisa, bem como os dados coletados configuram o presente artigo científico baseado em levantamento bibliográfico, que traz as informações que visam responder ao questionamento geral do estudo.
\end{abstract}

Palavras-chave: Adolescência; IST; Sexualidade; Aids; Enfermagem.

\begin{abstract}
This study has a qualitative approach and an explanatory-bibliographic character. It is based on Bonfim (2012), Nunes and Silva (2001), Valle and Mattos (2010), Benetti (1990), Costa e Silva (2019) Ministry of Health (2021) and among other authors who address the topic. The main objective sought to define the main causes and treatments of STIs in Brazil. It seeks to elucidate the following question: How can nursing contribute significantly to raising awareness of infections caused by STIs in adolescence? Initially, the concepts of AIDS in Brazil, STDs for STIs and Sexuality are presented. It is necessary to create the experience of an ethical, qualitative sexuality based on affective and bodily responsibility, especially in adolescence. Therefore, the specific objectives that enabled the results and understanding of this theme are: To carry out a brief history about the roots of adolescence and the beginning of AIDS in Brazil. Describe which are the most contagious frequent transmissible STIs for teenagers. Check how the health professional is essential for there to be adequate awareness among young people about their sexuality. Consider the possible forms of treatments for STIs and their application in today's daily life. Consider the role of the family in the search for the sexual understanding of young people. The research process, as well as the data collected, configure this scientific article based on a bibliographic survey, which provides information that aims to answer the general questioning of the study.
\end{abstract}

Keywords: Adolescence; STIs; Sexuality; Aids; Nursing.

\section{Resumen}

Este estudio tiene un enfoque cualitativo y un carácter explicativo-bibliográfico. Se basa en Bonfim (2012), Nunes y Silva (2001), Valle y Mattos (2010), Benetti (1990), Costa e Silva (2019) Ministerio de Salud (2021) y entre otros 
autores que abordan el tema. El objetivo principal buscó definir las principales causas y tratamientos de las ITS en Brasil, buscando dilucidar la siguiente pregunta: ¿Cómo puede la enfermería contribuir significativamente a la sensibilización sobre las infecciones causadas por las ITS en la adolescencia? Inicialmente se presentan los conceptos de SIDA en Brasil, ETS por ITS y Sexualidad, es necesario crear la experiencia de una sexualidad ética, cualitativa, basada en la responsabilidad afectiva y corporal, especialmente en la adolescencia. Por tanto, los objetivos específicos que permitieron los resultados y la comprensión de este tema son: Realizar una breve historia sobre las raíces de la adolescencia y el inicio del SIDA en Brasil. Describa cuáles son las ITS transmisibles frecuentes más contagiosas para los adolescentes. Compruebe cómo el profesional de la salud es fundamental para que exista una adecuada concienciación entre los jóvenes sobre su sexualidad. Considere las posibles formas de tratamiento para las ITS y su aplicación en la vida diaria de hoy. Considerar el papel de la familia en la búsqueda de la comprensión sexual de los jóvenes. El proceso de investigación, así como los datos recolectados, configuran este artículo científico a partir de una encuesta bibliográfica, que brinda información que tiene como objetivo dar respuesta al cuestionamiento general del estudio.

Palabras clave: Adolescencia; ITS; Sexualidad; SIDA; Enfermería.

\section{Introdução}

O presente trabalho tem como objetivo abordar como a IST tem ganhado espaço entre a população, principalmente a juvenil. A compreensão de fatores relacionados à adolescência e a IST se tornou algo fundamental nos dias atuais. A adolescência é um período especial, marcado pela busca de autonomia do jovem, bem como pelo desenvolvimento de habilidades e pela vivência da sexualidade. Há a necessidade de informações nessa fase, principalmente, devido aos desejos e transformações físicas e emocionais passam a agir de maneira constante. $\mathrm{O}$ adolescente passa a ter dificuldades em entender o próprio corpo e todas as mudanças que ocorrem neste período, com ela o desenvolvimento sexual acontece de maneira forte e acelerada. Este estudo visa contribuir de forma significativa para conscientização da IST e sua prevenção nesta fase primordial da vida.

A pesquisa traz os resultados e informações históricas relacionadas à AIDS no Brasil de forma sucinta. A DST passou a ser estudada de forma melhor e buscado recursos na saúde após o surto de AIDS no Brasil em 1980.

De tal modo, se visa esclarecer a importância da conscientização da IST na adolescência e entender qual a contribuição que a enfermagem pode trazer para a vida dos adolescentes. Verifica-se, ainda, como os pais podem ser a chave para que haja prevenção na adolescência.

O presente artigo científico é uma revisão sistemática de literatura visando trazer uma análise da IST na adolescência, esta pesquisa é fundamentada nos autores Nunes (2001), Valle e Mattos (2010), Santos e Costa (2019), Reis; Junqueira; Silva (2012), Andrade; Batista; Pinheiro (2018) Ministério da Saúde entre outros autores que abordam a temática.

O tema começou a ser estudado em meados do XIX, para compreender como a IST tem avançado na sociedade jovem, sendo necessária a análise de como se aborda a historicidade da Adolescência, os documentos que norteiam esta fase da vida das pessoas, e as contribuições da enfermagem e da família para o processo de conscientização. (Costa, 2019)

Parte-se de Santos e Costa (2019, p. 16) que retratam o surgimento da adolescência:

O termo "adolescência" foi utilizado somente em meados do século XIX, e só veio a ser introduzido como objeto de estudo científico, no campo da Psicologia, no século XX, por um viés estritamente psicológico pautado em perspectivas analíticas.

Neste aspecto a pesquisa define a adolescência e como tudo começou em baseamento cientifico e histórico dos autores Santos e Costa (2019) entre outros.

A relevância desta pesquisa tem como ponto fundamental auxiliar jovens no processo de conscientização e entendimento da sexualidade, tendo em vista que muitos jovens chegam no posto de saúde, desorientados e muitas vezes sem ao menos saber como contraiu algum vírus ou infecção. (Nunes, 2001) 
A adolescência é uma das fases primordiais da vida dos indivíduos e para chegar ao entendimento das IST é necessário um apoio integral da enfermagem, para que haja campanhas de conscientização, sobre um tema tão pouco trabalhado nos dias atuais, a sexualidade de jovens. (Bonfim, 2012)

Para que os profissionais da enfermagem possam ter acesso à determinada população juvenil, são necessárias campanhas em escolas e eventos culturais, além dos postos de saúde que são de grande relevância para a população. Porém, não se pode se restringir em apenas informar sobre os riscos de a IST, de modo que é necessário fazer o jovem ter consciência delas, e que sua prevenção vai muito mais além de preservativos. É necessário que haja investimentos em saúde pública para que assim possa haver campanhas inovadoras que contribuíam para a conscientização. O diálogo é a peça fundamental para que o enfermeiro possa conseguir atingir o adolescente, porém este diálogo deve ser feito de forma natural e sem tabus e preconceitos, saber ouvir é o começo para uma verdadeira atuação do enfermeiro nesta etapa. (Bonfim, 2012)

A atuação pode ocorrer em diversos momentos podendo ser através de palestras em escolas, banner, folder e dentro dos postos de saúde, também é necessário que o profissional esteja capacitado em dialogar com jovens e esteja preparado para possíveis perguntas, pois os jovens são questionadores de sua realidade. É necessário um treinamento adequado para que o enfermeiro esteja preparado para lidar com as adversas situações e problemas familiares que possam surgir. (Costa; Silva. 2019)

A questão norteadora que embasa esta pesquisa pode ser definida na seguinte sentença: De que maneira a enfermagem pode contribuir de forma significativa para a conscientização das infecções causadas pela IST na adolescência?

Os objetivos serão descritos e analisados nas secções seguintes da pesquisa, como objetivo central buscou-se definir quais as principais causas e tratamentos da IST no Brasil. Sendo assim, os objetivos específicos que possibilitaram os resultados e a compreensão desta temática são: Realizar um breve histórico sobre as raízes da adolescência e sobre o início da AIDS no Brasil. Descrever quais são as IST frequentes transmissíveis de maior contágio para os adolescentes. Verificar como o profissional de saúde é essencial para que haja uma conscientização adequada entre os jovens na sua sexualidade. Confrontar como a teoria pode ser útil na prática no cotidiano das pessoas, na sociedade que vivemos. Considerar as formas de tratamentos possíveis para a IST e sua aplicação no cotidiano atual.

Refletir e analisar porque a sexualidade ainda é baseada em tabus e preconceitos existentes na sociedade atual. Considerar o papel da família na busca do entendimento sexual dos jovens.

O processo de pesquisa, bem como os dados coletados configuram o presente artigo científico como levantamento bibliográfico e pesquisa qualitativa, que traz as informações que visam responder ao questionamento geral do estudo.

\section{Metodologia}

O presente estudo foi baseado na revisão sistemática de literatura visando trazer um panorama da temática abordada e como os adolescentes perpassam por esta fase da

Este artigo cieníifico teve como etapa da pesquisa a natureza básica tendo, como caráter teórico os estudos dos autores: Amaral; Santos (2017), Andrade; Batista; Pinheiro (2018) Bonfim (2012), Barros; Bossa (1998); Benetti; Ramos; Aragão e Vinha (2010) Ciriaco (2019) Figueiró (2013), Goretti; Pinheiro (2021), Santos; Costa (2019); Nunes(1987) entre outros autores que abordam o tema. Esta pesquisa utilizou de abordagem qualitativa e caráter explicativo.

Sobre a abordagem Qualitativa, Pádua (2003, p.34) afirma que estas "tem se preocupado com o significado dos fenômenos e processos sociais, levando em consideração as motivações, crenças, valores, representações sociais, que permeiam a rede de relações sociais". Nesta pesquisa os autores buscaram entender e apresentar formas de orientação para que haja uma educação sexual emancipatória. Os autores Nunes (1987) e Bonfim (2012) Figueiró (2013) conceituam e explicam a fase da adolescência. 


\title{
3. A aids (hiv) no Brasil e o Início das Doenças Sexualmente Transmissíveis
}

Não há como iniciar o estudo sobre a IST sem mencionar a Aids, um conceito que, ainda nos dias atuais, é muito estudado a fim de que se alcance a cura.Segundo Varella (2021) os primeiros casos do vírus surgiram em 1981 na California. Ressaltando Sousa et.al (2012) explica como é causado o vírus e qual sistema imunológico a HIV ataca:

\begin{abstract}
A AIDS é uma doença causada pelo vírus HIV e corresponde ao estágio mais avançado da infecção que ataca o sistema imunológico, ficando o organismo vulnerável a outras infecções. Os primeiros casos foram detectados em 1981 e a partir daí atingiu números alarmantes em todo mundo sendo considerada uma pandemia. O Brasil, atualmente, apresenta uma das políticas de enfrentamento à AIDS mais moderna do mundo, destacando-se a forte organização social para a formulação desta, o acesso às drogas terapêuticas, a mobilização da comunidade internacional e o movimento de reforma sanitária. (Sousa, et. al., 2012)
\end{abstract}

Após a epidemia da AIDS em 1981, foram enfrentadas situações difíceis, vez que se tratava de um vírus novo, sem nenhum estudo ou medicamentos que pudessem o combater, levando a um diagnóstico tardio que, muitas vezes, custava a vida do paciente. (Silva, et al., 2012).

Passado 30 anos do inicio da epidemia, Silva et al. (2013) salienta que com a marca do processo de heterossexualização, feminilização, pauperização e interiorização houve aumento no contato de transmissão através de contatos heterossexuais e nos casos femininos o que caracteriza um importante fenômeno atual na epidemia.

Silva (2013, p. 6040) ressaltam que:

Além do aumento significativo do número de mulheres em idade fértil infectados pelo HIV, merece atenção crescentes valores de idosos portadores deste vírus, o que caracteriza o processo de envelhecimento dessa epidemia e demonstra mais uma forte mudança no perfil da AIDS no Brasil. É importante salientar que esta transformação no panorama epidemiológico da AIDS acarreta também uma necessidade de conscientização e mudança no comportamento de todas as pessoas envolvidas na área da saúde que trabalham com o portador de HIV/AIDS.

Após entender o ano em que ocorreu o início da epidemia no Brasil, a população que foi atingida, é importante ressaltar as características do vírus HIV e como sua transmissão acontece. Segundo o Ministério da Saúde (BRASIL, 2021) a AIDS é causada pela Imunodeficiência Humana (HIV) que ataca o sistema imunológico.

A aids é a doença causada pela infecção do Vírus da Imunodeficiência Humana (HIV é a sigla em inglês). Esse vírus ataca o sistema imunológico, que é o responsável por defender o organismo de doenças. As células mais atingidas são os linfócitos T CD4+. O vírus é capaz de alterar o DNA dessa célula e fazer cópias de si mesmo. Depois de se multiplicar, rompe os linfócitos em busca de outros para continuar a infecção.

Sendo assim, sabe-se que para esta infecção existe tratamento, mas infelizmente a cura da doença, ainda é um dilema que se estende por muitos estudos científicos. Para Goretti e Pinheiro (2021) a transmissão ocorre:

O HIV é transmitido de uma pessoa para outra por sangue, sêmen, secreção vaginal e leite materno. O contágio ocorre, via de regra, por meio de relações sexuais desprotegidas, transfusões de sangue eprocedimentos com material contaminado ou contato com ferimentos.

Nos dias atuais com o tratamento adequado a HIV é combatida com remédios que, por sua vez, podem trazer muito mais acalanto ao portador, que pode viver sua vida de forma prazerosa e natural sem medo de ser feliz. O coquetel anti-HIV disponibilizado nos postos de saúde, procura auxiliar para que a pessoa portadora do vírus possa viver mais de forma saudável e vivenciar sua sexualidade usando preservativos, e se protegendo o mais simples e natural possível. Goretti e Pinheiro (2021) ressaltam como o coquetel age no organismo: 
Com o coquetel anti-HIV, uma combinação de drogas que atacam o vírus em diferentes estágios, as defesas do portador não vão ruir e, consequentemente, ele evita as complicações derivadas da imunodeficiência". No inicio do tratamento o paciente pode sentir alguns efeitos como vômito, diarreia, nauseia e insônia. Porém com o tratamento iniciado ao decorrer do processo o paciente poderá não sentir mais estes sintomas e viver de forma significativa sua vida.

\subsection{Da terminologia DST para IST}

Após o início da AIDS no Brasil, percebeu-se um grande aumento no número de infecções sexualmente transmissíveis. A Nomenclatura do termo DST para IST trouxe a diferenciação na questão doença para infecção, devido doenças arremeter a sintomas e a IST refere-se a também pessoas assintomáticas. O Ministério da Saúde (2017) explica essa diferenciação.

O Departamento de Doenças de Condições Crônicas e Infecções Sexualmente Transmissíveis passa a usar a nomenclatura "IST" (infecções sexualmente transmissíveis) no lugar de "DST" (doenças sexualmente transmissíveis). A nova denominação é uma das atualizações da estrutura regimental do Ministério da Saúde por meio do pelo Decreto $\mathrm{n}^{\circ}$ 8.901/2016 publicada no Diário Oficial da União em 11.11.2016, Seção I, páginas 03 a 17.“'A denominação 'D', de 'DST', vem de doença, que implica em sintomas e sinais visíveis no organismo do indivíduo. Já 'Infecções' podem ter períodos assintomáticas (sífilis, herpes genital, condiloma acuminado, por exemplo) ou se mantém assintomáticas durante toda a vida do indivíduo (casos da infecção pelo HPV e vírus do Herpes) e são somente detectadas por meio de exames laboratoriais" [...] (Brasil, 2017)

Esta nomenclatura foi importante para situação das pessoas com alguma contaminação. A IST tem tratamento e cura, são infecções causadas por algum vírus. Existem vacinas e tratamentos gratuitos. A mudança também ocorreu pelo fato de destacar a possibilidade de uma pessoa ter e transmitir uma infecção, mesmo não apresentando sinais e sintomas. (Brasil, 2017).

A transmissão desta infecção pode ocorrer de diversas maneiras, via contato vaginal, oral ou anal. Estas infecções também podem ser contraídas de maneira não sexual, seja por mucosas da pele não integra ou secreções corporais contaminadas (BRASIL, 2017).

Ainda conceituando a IST (Turbiani, 2019) Aponta que a OMS (Organização Mundial da Saúde) contabiliza dados alarmantes de contaminação. “Todos os dias, de acordo com a Organização Mundial da Saúde (OMS), são contabilizados no mundo mais de 1 milhão de casos de infecções sexualmente transmissíveis (IST) curáveis entre pessoas de 15 a 49 anos [...]”.

O importante ressaltar que a IST diferente do HIV tem cura, mas infelizmente muitas pessoas nem procuram o médico quando percebem algum sintoma diferente como: feridas, ou corrimento ou coceira, a falta de conscientização e informação frequentes, traz estes malefícios a saúde de muitas pessoas, principalmente entre os jovens. (Turbiani, 2019)

\subsection{Principais IST contraídas em jovens no Brasil}

As IST são agrupadas de acordo com as manifestações clínicas que elas apresentam, desta forma o tratamento e os sintomas são diagnosticados de forma mais rápida. Muitos adolescentes só percebem que contrairam alguma IST quando em meninas: ocorre a gravidez indesejada ou surgimento de verruga. Mesmo com campanhas da saúde pelas mídias socias os adolescentes possuem muito medo e até mesmo o preconceito em falar sobre o tema. Seja ele na escola, na família ou com um profissional de saúde. (Turbiani, 2019)

As principais e mais comuns IST são classificadas em quatro síndromes como aponta Santos e Costa (2019)

Por meio do exame físico e dos testes sorológicos é realizado o diagnóstico da IST e iniciado o tratamento com abordagem sindrômica. As ISTs são classificadas em quatro síndromes: úlceras genitais; corrimento vaginal e uretral, desconforto ou dor pélvica; lesões verrucosas. 
Estas quatro classificações possuem patologias que denominam cada síndrome em grupos, as mais comuns são: nogrupo das úlceras genitais estas cinco patologias envolvem sempre lesões na região vaginal. Dentre elas: Sífilis, Herpes simples ou Vírus herpes humano, cancroide ou cancro mole, linfo granuloma venéreo, Donovanose ou granuloma inguinal. (Reis, 2012)

A síndrome do corrimento vaginal e uretral envolve duas patologias que sempre vão estar ligadas a corrimentos pela vagina ou ureta masculina. Estas duas patologias são: Vanigite ou vaginoses e Uretrites. "A síndrome do desconforto ou dor pélvica ocorre por causa da migração dos microrganismos infecciosos da região genital para o endométrio, para as tubas uterinas e para a cavidade pélvica, afetando o peritônio.” (Santos; Costa, 2019)

E por último do grupo das síndromes que envolvem a IST, as lesões verrucosas que são causadas pelo vírus HPV (papilomavirus) que, em mulheres, desenvolve o câncer do colo do útero. As verrugas também são conhecidas como cristas de galo. As verrugas muitas vezes de desenvolvem na vagina, na vulva e na região anal. (Santos, Costa, 2019)

Os tratamentos para estas infecções são disponibilizados pelo sistema de saúde (SUS), porém muitas mulheres, tanto na fase adulta ou adolescente, não procuram tratamento, ou muitas vezes por não perceberem sintomas não fazem os exames de prevenção que são necessários, ao menos, uma vez ao ano quando se inicia a vida sexual, o exame preventivo. (Santos; Costa, 2019).

De forma sucinta todas estas infecções são causadoras de IST decorrem, principalmente, de quando a iniciação da vida sexual ocorre de maneira exacerbada ou desenfreada. Homens ou Mulheres que iniciam sua vida sexual a partir dos 15 anos muitas vezes nem percebem que se contaminaram com alguma. Para Reis; Junqueira; Rosa (2012) a prática da iniciação sexual na adolescência acontece por meio:

A escolha do momento da iniciação sexual pelo adolescente está fortemente ligada as tendências de comportamento do seu grupo em um dado momento. O mais importante fator preditivo de forte intenção de iniciação sexual por um adolescente é o fato de seus amigos já terem feito a iniciação.

A motivação para a iniciação sexual precoce decorre, além disso, de fatores como falta de informação, estímulo à erotização precoce pela mídia, desestruturação familiar, onipotência do adolescente, autoestima rebaixada, dentre outros. Os meios de comunicação, além de influenciarem o comportamento, podem ser um fator de distorção da sexualidade.

Devido este fator as práticas sexuais iniciam cedo, perante os meninos e fortemente as meninas são as mais prejudicadas com a sexualidade utilizada de forma banalizada. As meninas sempre sofrem mais que os meninos acarretando problemas a sua saúde sexual. (Santos; Costa, 2019).

\subsection{Sexualidade e a prevenção com a IST}

Para muitos jovens a sexualidade deve ser vivenciada de todas as formas, sem pudores, sem regras e, principalmente, sem preservativos. São tantos riscos e perigos que os jovens correm sem a prevenção adequada, mas a cada ano que passa percebe-se que a conscientização das IST fica cada vez mais distante dos objetivos dos jovens (Reis, 2012).

Muitos adolescentes na puberdade, na fase que estão conhecendo seu corpo e sentindo suas emoções e sentimentos na pele, no dia a dia entendem a sexualidade apenas como no sexo. Não sabem que ter uma vida saudável e sexualmente ativa, não é apenas chegar ao ato sexual, são carinhos, emoções, abraços, beijos, uma amizade, sentimentos de afeto pelo o outro, enfim, todas estas formas de sentimentos trazem uma sexualidade saudável, não só para os jovens, mas também para os adultos que muitas vezes, agem com preconceitos e tabus referente à sexualidade. (Nunes, 2001)

A sexualidade é desenvolvida desde o nascimento e a gestação da mãe, desde o afeto de uma mãe com o bebê até os primeiros anos de vida, ela está ligada ao ser humano em construção ao longo da vida. Segundo Luz e Carvalho (2009) o preconceito marca toda uma vida principalmente dentro da educação, a base para a quebra destes paradigmas: 
Estereótipos e preconceitos marcam a educação. A escola reproduz muito do que a sociedade tem esperado de comportamentosmasculinos e femininos. A delicadeza, fragilidade, a discrição, a passividade, o pudor e a emoção são ensinados para as meninas. Emcontrapartida, dos meninos, espera-se competitividade,agressividade, força e racionalidade. [...] De ambos os sexos esperam-se relações de heterossexualidade consideradas como forma "única"e correta de vivência da sexualidade.

Com a prevenção com a IST não é diferente, todos estes preconceitos enraizados na escola, na sociedade e na família perpassam para a saúde. A saúde deve ser neutra não se podediscriminarapontar ou proliferar palavras ofensivas a alguém, ou algum adolescente, por algum problema, seja ele sexual familiar ou outras instancias (Santos; Costa, 2019)

O enfermeiro, assim como o professor, não tem o direito de julgar o ocorrido e salientar o seu ponto de vista sobre a questão, mas sim fazer as devidas orientações para que não ocorra mais. Como é o caso de uma transmissão por IST às vezes o jovem chega ao posto ou hospital sem saber o que dizer e como contraiu alguma infecção tudo o que ele quer é uma palavra de afeto e carinho, sem criticas e descaso. Como acontece muito nas redes públicas e privadas, primeiro vem o julgamento dos profissionais, depois o tratamento, conforme descreve Ciriaco, et al. (2019):

O conhecimento sobre a atividade sexual não resulta em uma prática mais precoce. Em contrapartida, torna a atividade mais segura, por diminuir a frequência de IST e gravidez não planejada. Dentro do contexto estrutural da sociedade, existe uma culpabilização que envolve os adolescentes no que diz respeito às práticas sexuais. Isso ocorre devido ao paradigma de que a livre expressão da sexualidade é interpretada como um comportamento transgressor. Assim, muitos jovens evitam procurar conselhos relacionados a esse aspecto.

Ciriaco (2019) ressaltou que os jovens se sentem culpados em buscar orientações devido ao fato de muitas vezes iniciar às práticas sexuais cedo e com medo das punições dos pais.

A prevenção para a IST segundo a OMS (Organização Mundial da Saúde) deve ocorrer principalmente com o uso de preservativos, muitas vezes adolescentes por estarem em uma relação considerada segura, por ambas as partes, não usam preservativos, e podem ter contraído uma IST mesmo sem sintomas. Como se denota do enxerto publicado pelo Ministério da Saúde (2021):

Importante ressaltar que existem vários métodos anticoncepcionais; no entanto, o único método para evitar a gravidez que também tem eficácia para prevenção de IST é a camisinha (masculina ou feminina). Orienta-se, sempre que possível, realizar a dupla proteção: uso da camisinha e outro método anticonceptivo de escolha.

A camisinha masculina ou feminina pode ser retirada gratuitamente nas unidades de saúde.

Quem tem relação sexual desprotegida pode contrair uma IST. Não importa idade, estado civil, classe social, identidade de gênero, orientação sexual, credo ou religião. A pessoa pode estar aparentemente saudável, mas pode estar infectada por uma IST.

As pessoas entendem que apenas o uso de contraceptivos previne qualquer tipo de infecção e a gravidez. Porém se sabe que apenas o preservativo é o método mais seguro existente para a prevenção. (Ciriaco, et al., 2019)

Sempre que houver um diagnóstico de uma IST ou HIV é necessário orientar e informar o parceiro que o adulto, ou jovem se relacionou para tomar os cuidados e fazer o tratamento. Faz-se necessário informar sobre o risco de contágio, os cuidados e a necessidade de atendimento em uma unidade de saúde e as medidas de prevenção e tratamento (ex.: relação sexual com uso de camisinha masculina ou feminina até que a parceria seja tratada e orientada. (Brasil, 2021)

Por isso é importante entender as fases da adolescência e como tudo começa, a vida sexual dos adolescentes seus períodos de transição da infância para a juventude e como orientar e acolher nossos adolescentes para uma vida saudável em todos os âmbitos de sua vida. (Santos; Costa, 2019) 


\subsection{A adolescência e a IST: o início de tudo}

A fase da adolescência é um período marcado por transição e mudanças corporais, psíquicas e sociais, na qual o adolescente está em descobrimento do seu corpo, de seus sentimentos e de suas ações. (Ciriaco, et al., 2019)

O período marcado pelas intensidades, pois os jovens sentem tudo com muita intensidade, seja bom ou ruim. É o caso das amizades, do amor, da vaidade e do sexo. Quando iniciam a vida sexual é tudo muito intenso, porém as consequências podem ser para toda a vida. Uma sexualidade exagerada sem domínio do próprio corpo, de suas ações e de seus desejos. (Amaral, 2017)

Para Amaral (2017) a adolescência é marcada pela transição de uma fase para a outra:

A adolescência, segundo a Organização Mundial da Saúde (OMS), é caracterizada pelo período da infância à fase adulta, que corresponde à faixa etária de 10 a 19 anos. É nessa fase que ocorrem diversas transformações biológicas como o crescimento dos ossos, desenvolvimento dos órgãos e sistemas e amadurecimento das características sexuais secundárias. Observa-se, também, mudanças psicológicas que envolvem alteração dehumor, desejo de viver intensamente, atração sexual, questionamentos sobre a vida, necessidade de aceitação, formação de grupos, afirmação da identidade pessoal e sexual e a iniciação na vida sexual.

Estas mudanças contribuem significativamente para todo o processo de maturação do jovem para a vida toda. Para que haja uma adolescência saudável e uma contribuição para toda a vida é necessário haver uma educação sexual emancipatória, conforme descreve Bonfim (2010):

Acreditamos que a Educação Sexual, além de ser uma maneira eficaz para combater doenças sexualmente transmissíveis (DSTs) [sic], gravidez e preconceitos. A sexualidade deve ser considerada em suas múltiplas formas de manifestação, tais como desejo, prazer, medo, amor, paixão e sensibilidade, além da atividade reprodutiva. O profundo contraste entre a exposição exacerbada do corpo e da sexualidade, muitas vezes parecem impedir a melhora da qualidade de vida da população.

Nesta fase, o conceito de gênero também é muito forte na cabeça dos adolescentes, devido estarem iniciando seus desejos e percebendo sua identidade assim a opção sexual do adolescente começa a se definir primordialmente nesta fase.

Questões relacionadas à sexualidade são frequentes nos meios acadêmicos, escolares e familiares, no entanto, o conhecimento é fragmentado por ambos oslados. Muitas pessoas vêem a criança como se ela fosse assexuada, por isso, desconsideram a importância da educação afetiva e sexual desde a infância. Mas é preciso esclarecer, que a educação em sexualidade deve ser abordada em qualquer idade. (Amaral; Santos, 2017)

Os anseios por aprendizados sobre o assunto devem ser explicados pelos pais professores e na saúde pública através de palestras em escolas, no posto de saúde também através dos meios midiáticos. Inicialmente a partir das curiosidades individuais, através do diálogo e da escuta de forma ética, usando uma linguagem e explicação diferenciada para cada idade, fundamentando-se em informações científicas e adotando uma postura que não banalize as informações e tenha o respeito como alicerce fundamental para dialogar sobre essa responsabilidade biológica, psicológica e social. (Bonfim, 2012).

É determinante se destacar a função da escola, não apenas como mediadora de conhecimentos científicos, mas principalmente, como fonte de transmissão de valores e ideias em que servem de espelho para as crianças e adolescentes. Tudo que envolve a sexualidade começa na família e na escola, através do diálogo, quando isso não acontece é na saúde que as contradições da sexualidade desenfreada acarretam gravidez indesejada e infecções adversas sendo as mais comuns Sífilis, Herpes, Dores pélvicas, corrimento entre outras. Após todo este entendimento da sexualidade na adolescência vale ressaltar a seguir o papel do enfermeiro diante destes desafios. (Bonfim, 2012). 


\title{
3.5 O papel do enfermeiro perante as infecções (IST) e os jovens
}

É latente a necessidade de uma educação emancipatória para a sexualidade, porque muitos jovens não buscam orientações devido a medos, timidez e o preconceito. Esta necessidade é fundamental nos dias atuais, percebe-se que a escola como mediadora de conhecimentos teria que ser o primeiro lugar de onde vir estas informações. As palestras, por exemplo, são um meio de prevenção e cuidado que todas as escolas deveriam ter ao menos uma vez ao mês, por profissionais sérios como os da enfermagem. Falar sobre a sexualidade não é apenas orientar aos métodos contraceptivos e sim questionar a realidade dos jovens. (Bonfim, 2012).

Oliveira; Bossa (1998) completa que:

Muitas escolas se limitam a dar aulas de biologia sobre reprodução humana, explicando o funcionamento do aparelho genital do homem e da mulher como educação sexual. O que estão fazendo é contribuir para uma das características da nossa época que causa muita confusão do ponto de vista educativo. Implementam o discurso do sexo, porém nada fazem para orientar os jovens quanto ao comportamento sexual, e seus resultados indesejáveis: gravidez, doenças...

O Papel da enfermagem perpassa muito além da orientação, sobretudo quando se trata dos jovens, o diálogo sem julgamentos e com a orientação devida, traz benefícios a todos os jovens. Muitos adolescentes acreditam que se não usar preservativos não vão se contaminar ou as meninas engravidar na primeira relação sexual, isso é uma falsa ideia de sexualidade. Os adolescentes estão sempre utilizando do lema "eu posso" quando passam da idade dos 15 anos começam a contradizer os pais acreditando serem donos da verdade. Tudo que os pais orientam muitas vezes para ter cuidado, não utilizar bebidas alcoólicas, não usar drogas etc. São conversas soltas recomendações que muitas vezes não são seguidas. O dialogo entre as famílias sobre a sexualidade é raro os pais estão sempre presos nas amarras do passado, do pudor e da sociedade. O tradicionalismo das famílias em uma visão geral não permite dialogar de forma abrangente e aberta com os filhos. (Oliveira; Bossa 1998).

Para que a atuação do enfermeiro se dê forma significativa são necessárias políticas públicas de saúde sexual de qualidade, com investimentos na educação sexual, ou seja, na prevenção, no tratamento e na orientação, conforme rege Oliveira; Bossa (1998):

\begin{abstract}
Vários autores ressaltam que a gravidez na adolescência, além de ser problemática para a trajetória da vida dos jovens, é um problema social, levando-se em conta a precariedade dos serviços de saúde, quer para o atendimento pré e pósnatal, quer para os partos e programas de planejamento familiar, e pela probabilidade de que a gravidez dê lugar a um aborto feito em condições de insegurança, além da clandestinidade que cerca o caso para as mulheres. Por isso a necessidade de políticas públicas e programas de saúde sexual nas escolas, para contribuir com a orientação adequada e séria aos adolescentes, para que eles possam tomar ciência de como lidar com sua sexualidade. Os enfermeiros como profissionais de saúde com uma formação generalista, atuam nas diversas áreas como preventivas, curativas e, na educação em saúde, a saúde dos adolescentes constitui uma interface da sua atuação.
\end{abstract}

Seu papel como profissional de saúde se estende além da prevenção, mas infelizmente não há um alicerce para que a enfermagem tenha completo domínio na orientação dos jovens. Tudo que visa investimento falta na saúde pública e principalmente em programas que visam a sexualidade, porque os investimentos em saúde sempre são relacionados a casos agravantes de saúde, porém a realidade dos jovens deveria ser fundamental para as políticas governamentais. (Bonfim, 2012)

\subsection{O papel da família na sexualidade dos jovens perante as IST}

A família como mediadora de conflitos em casa, tem como papel primordial conviver em comum acordo com a escola apoiando as decisões da escola para melhorar e ajudar os filhos quando passam por situações difíceis. É importante destacar que os pais como alicerce na família precisam dialogar com os filhos e quando houver dúvidas de como orientar na prevenção 
e tratamentos de IST é importante procurar uma Unidade de Atendimento (SUS) para conversar e dialogar com um enfermeiro que entenda as necessidades de cada família.

Partindo da premissa que a educação sexual informal também é relevante, Figueiró (2013), diz que:

Por meio de suas atitudes, falas, comentários, olhares, gestos, silêncios, enfim, de todo seu comportamento verbal e não verbal, as pessoas vão influenciando a criança ou o adolescente, desde o nascimento e ao longo de toda a sua vida, na formação de suas ideias e valores sobre corpo, abraço, beijo, namoro, relação sexual, carinho, nudez, parto, vida a dois e assim por diante. [...] Ou seja, adultos e idosos, por meio da educação sexual informal, também vão reeducando-se ao longo da vida, até o final de seus dias.

Por isso, frisa-se que a educação sexual informal é importante para os adolescentes, mas é necessário que na escola os preconceitos estabelecidos sobre a sexualidade sejam descontruídos pautados no conhecimento cientifico e seja tratada de forma significativa para o adolescente. Temos nas mãos das escolas a tarefa de sistematizar saberes e ensinar o aluno a fazer uma leitura crítica da realidade em que vive. E com a sexualidade não é diferente (ANDRADE, 2021).

Para Nunes (1987, p.14) “A sexualidade é uma das mais importantes e complexas dimensões da condição humana”. Nesta concepção, entende-se que quando a pessoa não é feliz não compreende a sua própria sexualidade, vive em conflito consigo e com os outros que o rodeiam.

Para Benetti (1990, p.61), a adolescência é a fase de transição:

A adolescência é fase de transição, de conflitos de identidade: o jovem está sujeito à ação de agentes sociais contraditórios (escola, família, colegas, meios de comunicação). Mesmo assim, uma crise de identidade profunda a ponto de ser traumática afeta pequeníssima minoria de jovens. Na grande maioria dos casos, as relações com os pais, embora cheias de desencontros, basicamente são positivas. Os próprios valores do grupo de colegas, quando se trata decisões importantes, mostram-se afinal compatíveis com os dos adultos, e os distúrbios patológicos não são mais graves na adolescência que nas outras faixas etárias.

Essa transição além de ser complexa, em alguns casos é angustiante, especialmente quando pais não conseguem entender o que se passa com os filhos. Trabalhando conceitos de violência na escola verifica-se que começam por volta dos 13 anos Ramos, Aragão e Vinha (2010, p.126) considerando Diaz-Aguado, afirmam que:

[...] a violência nas escolas, principalmente entre os adolescentes, chega a seu ápice por volta dos 13 anos, pois nessa fase, há maior incerteza sobre a própria identidade, uma integração em grupos de referência, as situações de frustações e tensões e, principalmente, os desajustes entre as necessidades dos adolescentes em relação às condições escolares e familiares.

Por conseguinte, resta claro que a família e a enfermagem, fazem papel mediador em todo o processo de desenvolvimento e maturação dos jovens. Uma orientação adequada através de um diálogo consciente traz benefícios valiosos para que as IST não predominem na relação dos adolescentes com os pais, escola e saúde. Buscando mediar estes conflitos e estabelecer uma união em prol do bem-estar do adolescente e de todas as pessoas com as quais ele convive. (Bonfim, 2012)

\section{Resultados e Discussão}

Sabe-se que a IST tem tratamento e prevenção a autora Ciriaco (2019) descreve a importância dos métodos para esta fase. E Santos e Costa (2019) ressaltam como é necessário conhecer cada infecção para saber tratar.

Bonfim ressalta (2012) que durante as fases da infância para a vida adulta a educação sexual deve ser pautada: Durante a infância na descoberta da sexualidade. Durante a adolescência nas Manifestações da sexualidade. E por fim na Idade Adulta em Referenciais para a vivência sexualidade. 
Existe uma grande gama de artigos sobre o tema proposto, contudo, considerando as delimitações anteriormente realizadas, chegou-se a 10 artigos que contribuíram de forma efetiva para a elaboração do presente trabalho, sendo eles: Amaral; Santos (2017), Andrade; Batista; Pinheiro (2018) Bonfim (2012), Barros; Bossa (1998); Benetti; Ramos; Aragão e Vinha (2010) Ciriaco (2019) Figueiró (2013), Goretti; Pinheiro (2021), Santos; Costa (2019); Nunes (1987).

Dentre eles, destaca-se a importância do material elaborado por Bonfim (2012), que aborda a temática de uma maneira clara e objetiva, de fácil leitura e compreensão, bem como o que fora disposto por Turbiani (2021), que segue na mesma linha do material anteriormente disposto.

Há a necessidade de auxílio às crianças e os adolescentes para se construir com naturalidade a descoberta do corpo, a construir sua auto-estima e atribuir significados e referências para que na fase adulta possam compreender e vivenciar a sua própria sexualidade com tranquilidade e de maneira prazerosa, afetiva, plena e qualitativa. (Bonfim 2012)

Os resultados obtidos tiveram seu alicerce baseado na teoria que o enfermeiro pode ser muito mais que exercer a prevenção do adolescente, a enfermagem pode além de tudo saber ouvir e dialogar com os adolescentes e suprir todas as suas dúvidas a respeito da sexualidade. As teorias apresentadas demonstram que faltam um alicerce na escola, na família e na sociedade. Sabe-se que apenas através de programas de saúde pública que funcionem os adolescentes sentirão mais seguros, em falar e desmitificar os preconceitos existentes referente ao tema.

\section{Considerações Finais}

A questão da sexualidade não é meramente informar os nossos jovens, mas orientar, possibilitando que eles desenvolvam a consciência crítica, esclarecendo anseios existentes oferecendo espaços para que possibilitem reflexões aos nossos adolescentes, para que construam sua própria identidade ética e estética sem ultrapassar a educação familiar e libertarem-se das amarras mercantilista da sociedade capitalista.

É fundamental debater com os adolescentes assuntos como gravidez, IST, ditadura da beleza, corpo, saúde sexual, exploração sexual-comercial de adolescentes, estereótipos midiáticos, relacionamentos virtuais sociais e os conceitos primordiais que abrangem a sexualidade, buscando sempre formar a consciência crítica, visando à superação de concepção moralista e repressora da adolescência.

Entender os adolescentes não é tarefa fácil, mas devemos estar aptos a aprender novos meios e técnicas para lidar nas mais diversas situações do cotidiano seja ele na sociedade, família ou na saúde. A instabilidade que os caracteriza não é sintoma de desiquilíbrio, nem de doença. O receio de perguntar e dialogar sobre suas dúvidas e inquietações com as pessoas que os rodeiam geram conflitos interiores ainda maiores. Os adolescentes sentem-se desorientados e preocupados na medida em que vêem os pais angustiados por causa deles. A tarefa mais difícil é conseguir fazer os pais compreenderem que a comunicação tranquila, sem desgastes emocionais é sempre o melhor caminho, no entendimento dos adolescentes.

Ao longo deste trabalho, buscou-se descrever questões sobre a sexualidade na adolescência, com o intuito de levantar reflexões e diferenciações sobre a fase da adolescência e a importância do entendimento das infecções estarem presente a todo momento na vida sexual dos adolescentes, estas inquietações a respeito deste tema, surgem a todo o momento.

É necessário o enfermeiro estar preparado para as perguntas frequentes que possam surgir a respeito da temática, os jovens não sabem muito bem como fazer perguntas, que querem saber uma resposta. Porém o enfermeiro deve estar aberto a perceber estas dúvidas dos jovens e levá-lo ao questionamento, para que assim os adolescentes percam o medo e a timidez, e estejam preparados para vivenciar sua sexualidade.

Em relação a temática abordada, entende-se pela necessidade de continuidade de estudos no ramo, vez que com o avanço tecnológico, pode ser que os jovens e adolescentes passem a ter contato com informações erradas sobre o tema, as famosas fake news, de modo que é de extrema importância que haja uma conscientização correta e aberta sobre o tema por 
meio de políticas públicas conveniadas aos órgãos de saúde. Há de se salientar a importância do uso de preservativo e de exames de rotina.

\section{Referências}

Amaral, S. M. A., Santos, D., Paes, H. C. S., Dantas, I. S \& Santos, D. S. S. (2017). Adolescência, Gênero E Sexualidade: Uma Revisão Integrativa. Revista Enfermagem Contemporânea, 6(1), 62-67. https://doi.org/10.17267/2317-3378rec.v6i1.1114

Andrade, B. J. M, Batista, O. T. M., \& Pinheiro, A. G. (2018). Sexualidade Infantil No Século Xxi: Entre Lacunas E Possibilidades. Revista de Pesquisa Interdisciplinar. 3(1). 131-141.

Benetti, G. R. (1990). Adolescência: notas de psicologia. Ed. Paulinas.

Brasil. (2016). Ministério Da Saúde. Departamento passa a utilizar nomenclatura "IST" no lugar de "DST". http://www.aids.gov.br/ptbr/noticias/departamento-passa-utilizar-nomenclatura-ist-no-lugar-de-dst.

Brasil. (2021). Ministério da Saúde. Infecções Sexualmente Transmissíveis. http://www.aids.gov.br/pt-br/publico-geral/o-que-sao-ist

Ciriaco, C. L. N., Pereira, C. A. A. L., Campos, P. H. A., \& Costa, R. A. A importância do conhecimento sobre Infecções Sexualmente Transmissíveis (IST) pelos adolescentes e a necessidade de uma abordagem que vá além das concepções biológicas. Em Extensão. 18(1). http://www.seer.ufu.br/index.php/revextensao/article/view/43346/26931.

Bonfim, C. (2012). Desnudando a Educação Sexual. Papirus.

Figueiró, D. N. M. (2013). Educação sexual no dia a dia. Eduel.

Goretti, T., Pinheiro. C. (2021) O que é aids, dos sintomas iniciais ao tratamento, passando pelos exames. Veja Saúde. https://saude.abril.com.br/medicina/oque-e-aids-dos-sintomas-iniciais-ao-tratamento-passando-pelos-exames/.

Luz, S. N., Carvalho, G. M., \& Casagrande, S. L. (2009) Construindo a Igualdade na Diversidade: gênero e sexualidade na escola. UTFPR.

Medeiros, B. J. (2005) Redação Cientifica. 7. Atlas S.A.

Nunes, C. (1987) Desvendando a sexualidade. Papirus.

Silva, E. (2001) Sexualidade(s) adolescentes(s): uma abordagem didática das manifestações da sexualidade na adolescência. Sophos.

Pádua, E. M. M. (2003). Metodologia da Pesquisa: abordagem teórico-prática. Papirus.

Reis, R. M. D., Junqueira, F. R. R., \& Rosa-E-Silva, A. C. J. D. S. (2012) Ginecologia da Infância e Adolescência. Artmed Grupo A. https://integrada.minhabiblioteca.com.br/\#/books/9788536327358/.

Santos, E. P. D., \& Costa, A. D. A. Z. (2019). Cuidado integral à saúde do adolescente. Grupo A. https://integrada.minhabiblioteca.com.br/\#/books/9788595029446/.

Silva, R. A. R. \& Duarte, S. H. F. (2013) A Epidemia Da Aids No Brasil: Análise Do Perfil Atual. Revista de Enfermagem UFPE Online. 10.5205/reuol.4377$36619-1$

Sousa A. M., de, Lyra A., de Araújo, C. C. F. Pontes, J. L., Freire, R. C., \& Pontes, T. L. A política da AIDS no Brasil: uma revisão da literatura. J Manag Prim Health Care.

Turbiani. R. (2018). Infecções sexualmente transmissíveis estão em alta no Brasil. BBC NEWS. <https://www.uol.com.br/vivabem/noticias/bbc/2019/11/1 6/infeccoes-sexualmente-transmissiveis-estao-em-alta-no-brasil-saiba-se-proteger.htm?cmpid

Oliveira, B. V. \& Bossa, A. N. (1998). Avaliação psicopedagógica do adolescente. Vozes.

Valle, R. L. E. L., \& Mattos, M. V. J. M (2010). Adolescência: as contradições da idade. Wak. 